\title{
Using F2 transition parameters in distinguishing Persian affricates from homorganic consonants
}

Zahra Mahmoodzade and Mahmoud Bijankhan

Linguistics Department, University of Tehran, Iran

https://doi.org/10.36505/ExLing-2008/02/0039/000098

\begin{abstract}
F2 transition parameters including F2 onset and offset frequency and locus equations have been studied for Persian affricates $/ \mathrm{d} z, \mathrm{t}$ and homorganic dental plosives $/ \mathrm{d}, \mathrm{t}$ / and post alveolar fricatives $/ 3, \mathrm{~S} /$. The F2 offset frequencies hierarchy is follow: post alveolar fricatives $>$ affricates $>$ dental plosives. This parameter makes a significant difference among mentioned consonants; however it does not show voicedunvoiced contrast. F2 onset does not provide regular results and locus equations coefficients do not show a significant difference between affricates and homorganic consonants.
\end{abstract}

Keywords: Persian, affricates, homorganic consonants, F2 transition parameters

\section{Introduction}

Vocalic parameters in consonant-vowel boundaries are important acoustic cues in consonant identification. Dorman et al. (1980) found that vocalic portion is an important acoustic cue in fricative-affricate contrast in word final position. In the previous studies, we investigated different acoustic parameters for making contrast between Persian affricates $/ d_{3}, t /$ and homorganic dentals /d, t/ and fricatives /3, S/ (Heselwod et al. 2008, Mahmoodzade and Bijankhan 2007). In this paper, F2 transition parameters including F2 onset and offset frequencies and also locus equations in the vocalic portion have been selected for studying the mentioned contrasts. These parameters are investigated mainly as acoustic cues demonstrating place of articulation differences in stops (Sussman et al. 1991, Kewley-Port 1982) and also fricatives (Jongman 2000, Whalen 1991). Some experiments used them for differences in manner of articulation too (Fowler 1994, Dorman et al 1980).

\section{Elicited Data and Measurements}

Ten male native speakers of Standard Persian (Farsi), aged between 20-40 years, were recorded producing isolated word forms with affricates $/ d_{3}, t /$ and homorganic fricatives $/ 3, \mathrm{~J} /$ and plosives $/ \mathrm{d}, \mathrm{t} /$ in the vocalic contexts /'$\mathrm{aC}_{2} /, / \mathrm{Ca}{ }^{\prime}-\mathrm{aC} /$ and $/{ }^{\prime} \mathrm{Ca}-/$ in initial, medial and final positions. Four repetitions of the word list were produced. There were 720 tokens altogether. The data was sampled at the rate of $22050 \mathrm{~Hz}$. The recording and analyzing

ExLing 2008: Proceedings of 2nd Tutorial and Research Workshop on Experimental Linguistics, 25-27 August 2008, Athens, Greece 
of data was done by using CSL 4400 Main Program. Both post and preconsonantal F2 transitions parameters were studied. ANOVA test (SPSS package 13) used for statistical analyses.

F2 onset Frequency is the frequency of second formant at the starting point of transition and was measured for affricates and homorganic consonants at the initial and medial position by calculating formants history on the spectrogram and determined at point after the release phase of consonants. The release of affricates /d, $\mathrm{t} /$ and plosives /d, t/ is accompanied with friction and aspiration (Heselwood et al. 2008), therefore the onset was determined at end of friction before aspiration. In the case of voiced unaspirated stops, the onset was determined at the first glottal pulse after the release. For fricatives $/ 3, \mathrm{~J} /$, the onsets were determined at the first glottal pulse after frication phase following Sussman and Shore (1996). FFT spectrum was calculated and F2 onset was measured manually.

F2 offset frequency is the frequency of second formant at the end of transition. The method for measuring F2 offset frequency is like F2 onset frequency, except the locus was determined for affricates and plosives at the last glottal pulse before closure and for fricatives before frication in medial and final position.

Locus equations "cue place indirectly by quantifying directly the degree of coarticulatory overlap (coarticulation resistance) between consonant and vowel" (Fowler, 1994). Locus equations coefficients, slope and y-intercept were measured following sussman et al. (1991) by plotting F2 onset or offset frequencies on the y-axis and F2 steady state frequencies on the x-axis. F2 steady state was determined visually following Sussman et al. (1991) and measured like F2 onset or offset frequencies. The regression lines traced on these points and the correlation coefficient $(\mathrm{R})$ and regression functions coefficients calculated by using SPSS software.

\section{Results and Discussion}

The mean values of F2 offset frequencies are given in table 1. ANOVA tests show that this parameter can make a significant difference between consonants in medial $\left(\mathrm{F}_{(5,234)}=26.4, \mathrm{p}<0.05\right)$ and final position $\left(\mathrm{F}_{(5,234)}=\right.$ 40.7, $\mathrm{p}<0.05)$. LSD Post Hoc tests show the following same results both for medial and final positions: 1) There is not a significant difference between $/ \mathrm{d}-\mathrm{t} /, / \mathrm{d}-\mathrm{t} /, / \mathrm{z}^{-} \mathrm{S} /$ pairs $(\mathrm{p}>0.05)$. 2) There is a significant difference between $/ d b^{-} d /$ and $/ d z-3 /$ pairs $(p<0.05)$. 3) There is a significant difference between $/ t-t /$ and $/ t-\int /$ pairs $(p<0.05)$. 4) There is a significant difference between $/ \mathrm{z}^{-} \mathrm{d} /$ and $/ \mathrm{S}-\mathrm{t} /$ pairs $(\mathrm{p}<0.05)$. 
Table 1. Offset frequencies results in Hz.

\begin{tabular}{|l|l|l|l|l|}
\hline \multirow{2}{*}{ Consonants } & \multicolumn{2}{|l|}{ Medial Position } & Final Position \\
\cline { 2 - 5 } & Mean & St. Deviation & Mean & St. Deviation \\
\hline d & 1749 & 87.4 & 1733 & 95.9 \\
\hline $\mathfrak{f}$ & 1760 & 89.5 & 1740 & 90.1 \\
\hline $\mathrm{d}$ & 1598 & 101.9 & 1586 & 86.6 \\
\hline $\mathrm{t}$ & 1552 & 186.7 & 1587 & 74.7 \\
\hline 3 & 1822 & 221.3 & 1848 & 149.2 \\
\hline $\mathbf{S}$ & 1841 & 134.8 & 1819 & 144.6 \\
\hline
\end{tabular}

The statistical analysis of F2 onset frequencies in initial and medial position does not provide regular results for relying on. Locus equations coefficients do not show a significant difference between the mentioned consonants in initial, medial and final positions, both in post and preconsonantal positions.

Results demonstrated that only pre-consonantal F2 offset frequencies can make a significant difference between Persian affricates and homorganic consonants. This parameter shows both contrasts in place and manner of articulation. There is a significant difference between F2 offset frequencies before closure and friction. One reason that F2 onset frequencies do not provide such a classification could be that F2 onset was measured after release burst therefore frequency differences decrease at this time as a result of closure opening. The mean F2 offset frequencies hierarchy is as follow: post alveolar fricatives $>$ post alveolar affricates $>$ dental plosives. Wilde (1993) and Jongman et al. (2000) found that in a given vowel context, F2 onset is progressively higher as the place of constriction moves back in the oral cavity. Our results with offset frequencies show that F2 offset frequencies of $/ 3, S /$ is higher than $/ d z, y /$, therefore the place of articulation of fricatives is further back in relation to affricates. Another matter is that there is no significant difference in F2 offset frequencies between voiced and voiceless pairs; this is the same result that Jongman et al. (2000) found by comparing F2 onset frequencies between voiced and voiceless labiodental, dental and alveolar English fricatives.

\section{References}

Dorman et al. 1980. Acoustic cues for a fricative-affricate contrast in word-final position. J. Phonetics, Vol. 8, 397-405.

Fowler, C. 1994. Invariants, specifiers, cues: An investigation of locus equations as information for place of articulation. Percept. Psychophys. 55(6), 597-610.

Heselwood, B. and Mahmoodzade, Z. 2007. Vowel onset characteristics as a function of voice and manner contrasts in Persian coronal stops. Leeds working Papers in linguistics and Phonetics, Vol. 12, 125-142. 
Heselwood, B., Mahmoodzade, Z., Bijankhan, M. 2008. Phonetic differences distinguishing Persian coronal plosives from affricates between release and vowel onset. BAAP, Sheffield, 31 March - 2 April.

Jongman et al. 2000. Acoustic characteristics of English fricatives. J. Acoust. Soc. Am. 108(3), 1252-1263.

Kewley-Port, D. 1982. Measurement of formant transitions in naturally produced stop consonant-vowel syllables. J. Acoust. Soc. Am.72(2), 379-389.

Mahmoodzade, Z and Bijankhan, M, 2007. Acoustic analysis of the Persian fricative-affricate contrast. ICPHS XIV, Saarbrucken, 6-10 August.

Sussman, H. M., McCaffrey, H. A., Matthews, S., A. 1991. An investigation of locus equations as a source of relational invariance for stop place categorization. J. Acoust. Soc. Am. 90(3), 1309-1325.

Sussman, H. M. and shore, J. 1996. Locus equations as phonetic descriptors of consonantal place of articulation. Percept. Psychophys. 58, 936-946.

Whalen, D. H. 1991. Perception of the English /s/-/S/ distinction relies on fricative noises and transitions, not on brief spectral slices. J. Acoust. Soc. Am. 90(4), 1776-1785.

Wilde, L. 1993. Inferring articulatory movements from acoustic properties at fricative vowel boundaries. J. Acoust. Soc. Am. 94, 1881. 